\title{
PROFIL DERMATITIS KONTAK DI POLIKLINIK KULIT DAN KELAMIN BLU RSUP PROF DR. R. D. KANDOU MANADO PERIODE JANUARI - DESEMBER 2012
}

\author{
${ }^{1}$ Yurike Sunaryo \\ ${ }^{2}$ Herry E. J. Pandaleke \\ ${ }^{2}$ Marlyn G. Kapantow \\ ${ }^{1}$ Kandidat Skripsi Fakultas Kedokteran Universitas Sam Ratulangi Manado \\ ${ }^{2}$ Bagian/SMF Ilmu Kesehatan Kulit dan Kelamin Fakultas Kedokteran Universitas Sam \\ Ratulangi Manado \\ Email: yurikesunaryo10_006@yahoo.co.id
}

\begin{abstract}
Contact dermatitis is a skin inflamatory response caused by direct contact with materials or particular substances. Contact dermatitis is classified into two types: irritant contact dermatitis (ICD) which is a non-immunologic response and allergic contact dermatitis (ACD) which is caused by immunologic mechanisms, type IV hypersensitivity reaction. This study aimed to evaluate the profile of contact dermatitis in patients of Dermatovenereology clinic at Prof. Dr. R. D. Kandou Hospital Manado during the period from January 2012 December 2012. This was a retrospective study of 77 medical records of new patients with contact dermatitis based on number of patients, age group, sex, occupation, affected location, causes, and treatment used. The results showed that among 77 new patients with contact dermatitis, the highest age group was 45-64 years (37.7\%), more often in female $(67.5 \%)$, most frequent occupation was homemaker (24.7\%), most location affected was leg (26\%), most common causes were detergent and rubber (13\%), and the most therapy used was a combination of corticosteroid and antihistamine (42.8\%). Conclusion: Among patients of Dermatovenereology clinic at Prof. Dr. R. D. Kandou Hospital Manado contact dermatitis was most frequently found in age group 45-64 years, female gender, and occupation as house wife. Leg was the most affected site, detergent and rubber as the main causes, and combination therapy as the most frequent therapy used.
\end{abstract}

Keywords: contact dermatitis

\begin{abstract}
Abstrak: Dermatitis kontak adalah peradangan kulit sebagai respon terhadap bahan atau substansi tertentu yang berkontak dengan kulit. Dermatitis kontak diklasifikasikan menjadi 2 bagian besar, yaitu dermatitis kontak iritan (DKI) yang merupakan respon non imunologik dan dermatitis kontak alergi (DKA) yang diakibatkan oleh mekanisme imunologik, reaksi hipersensitivitas tipe IV. Penelitian ini bertujuan untuk mengetahui profil pasien dermatitis kontak di Poliklinik Kulit dan Kelamin RSUP Prof. Dr. R. D. Kandou Manado periode Januari 2012 - Desember 2012. Penelitian ini merupakan penelitian retrospektif dari 77 catatan medik pasien baru dermatitis kontak berdasarkan jumlah pasien, umur, jenis kelamin, pekerjaan, lokasi, penyebab, dan terapi. Hasil penelitian menunjukkan bahwa dari 77 orang (7,02\%) pasien baru yang berkunjung, didapatkan kelompok usia terbanyak 45-64 tahun (37,7\%), jenis kelamin perempuan (67,5\%), pekerjaan terbanyak ibu rumah tangga $(24,7 \%)$, lokasi terbanyak yaitu kaki (26\%), penyebab terbanyak ialah detergen dan karet (13\%), serta terapi yang terbanyak digunakan kortikosteroid dan antihistamin (42,8\%). Simpulan: Pada
\end{abstract}


pasien dermatitis kontak di Poliklinik Kulit dan Kelamin RSUP Prof. Dr. R. D. Kandou Manado yang terbanyak kelompok usia 45-64 tahun, jenis kelamin perempuan, pekerjaan ibu rumah tangga, lokasi tersering kaki, penyebab tersering deterjen dan karet, serta pemberian terapi tersering ialah kombinasi kortikosteroid dan antihistamin

Kata kunci: dermatitis kontak

Dewasa ini seiring dengan peningkatan perkembangan industri dan perubahan dibidang pembangunan secara umum di dunia, terjadi perubahan dalam pembangunan baik dalam bidang teknologi maupun industri. Pekerjaan dibidang industri dan teknologi mempermudah pekerja terpapar dengan bahan-bahan iritan dan alergik. Sebagai konsekuensinya terjadi perubahan pola penyakit karena hubungannya dengan pekerjaan. Salah satu penyakit kulit yang terkait dengan masalah tersebut adalah dermatitis kontak.

Dermatitis kontak / contact eczema adalah peradangan kulit sebagai respon yang disebabkan oleh bahan atau substansi tertentu yang kontak dengan kulit. ${ }^{1,2}$ Dermatitis kontak diklasifikasikan menjadi 2 bagian besar, yaitu dermatitis kontak iritan (DKI) yang merupakan respon nonimunologik dan dermatitis kontak alergi (DKA) yang diakibatkan oleh mekanisme imunologik, reaksi hipersensitivitas tipe IV. ${ }^{3,4}$

Penderita dermatitis kontak iritan lebih banyak dibandingkan dengan dermatitis kontak alergi yaitu sebanyak $80 \%$, sedangkan dermatitis kontak alergi hanya 10-20\%. Hal ini disebabkan karena dermatitis kontak alergi hanya mengenai orang yang kulitnya hipersensitif., Dermatitis kontak mengenai semua usia tetapi lebih sering diderita oleh orang dewasa dan tertinggi pada usia produktif 2544 tahun. Dari jenis kelamin terjadinya dermatitis kontak lebih banyak wanita daripada pria. Menurut predileksi dermatitis kontak paling sering di tangan, karena tangan merupakan bagian organ yang paling sering digunakan untuk pekerjaan seharihari. ${ }^{1,5}$ Penderita penyakit ini berhubungan dengan pekerjaan. Diantara pasien usia kerja, penyakit kulit menempati urutan ketiga dari seluruh penyakit akibat kerja pada umumnya, dengan kejadian dermatitis kontak sendiri 70-90\% dari semua penyakit akibat kerja. ${ }^{6,7}$

Dermatitis kontak adalah umum dipopulasi, dengan prevalensi dermatitis tangan 9,7\% dan kejadian 5,5-8,5/1000 orang pertahun. ${ }^{7}$ Di Amerika serikat, sebesar $90 \%$ dari semua penyakit kulit akibat kerja dan menyumbang hampir 6 juta kunjungan ke dokter setiap tahunnya. ${ }^{4}$ Dari Indonesia penelitian Poliklinik Kulit dan Kelamin RSUP Manado periode Januari 2001 - Desember 2005 didapatkan jumlah penderita dermatitis kontak 1.198 orang atau $5,51 \%$ dari 21.741 orang penderita penyakit kulit rawat jalan. $^{8}$

Dengan insidensi dermatitis kontak yang cukup banyak maka diperkirakan jumlah penderita dermatitis kontak, baik alergi maupun iritan, akan mengalami peningkatan insidensinya seiring dengan perkembangan pembangunan diberbagai bidang industri dan teknologi karena bertambahnya berbagai produk bahan kimia yang digunakan oleh masyarakat umumnya, sehingga peneliti tertarik untuk melakukan penelitian lebih lanjut tentang profil pasien Dermatitis Kontak di Poliklinik Kulit dan Kelamin BLU RSUP Prof. Dr. R. D. Kandou Manado periode Januari Desember 2012.

\section{METODOLOGI PENELITIAN}

Penelitian ini bersifat deskriptif retrospektif dengan mengevaluasi catatan rekam medik pasien dermatitis kontak di Poliklinik Kulit dan Kelamin BLU RSUP Prof. Dr. R. D. Kandou Manado periode Januari - Desember 2012. Lokasi Penelitian ini dilakukan di Poliklinik Kulit dan Kelamin dan pusat rekam medik RSUP Prof. Dr. R. D. Kandou Manado selama 2 
bulan dari bulan November 2013 sampai dengan Desember 2013. Populasi penelitian adalah seluruh data pasien baru yang berobat di Poliklinik Kulit dan Kelamin RSUP Prof. Dr. R. D. Kandou Manado periode Januari - Desember 2012. Sampel penelitian adalah semua pasien baru yang terdiagnosa dengan dermatitis kontak yang berobat di Poliklinik Kulit dan Kelamin RSUP Prof. Dr. R. D. Kandou Manado periode Januari - Desember 2012. Variabel penelitian yaitu umur, jenis kelamin, pekerjaan, lokasi, penyebab dan terapi.

\section{HASIL PENELITIAN}

Berdasarkan penelitian retrospektif yang dilakukan di bagian Kulit dan kelamin serta Rekam Medik RSUP Prof. dr. R. D. Kandou Manado tentang profil dermatitis kontak periode Januari - Desember 2012 maka hasil penelitian tersebut disajikan dalam bentuk tabel sebagai berikut:

Tabel 1. Jumlah kasus tahun 2012

\begin{tabular}{|c|c|c|c|}
\hline TAHUN & $\begin{array}{c}\text { Jumlah } \\
\text { Penderita } \\
\text { Dermatitis } \\
\text { Kontak }\end{array}$ & $\begin{array}{c}\text { Jumlah } \\
\text { Penderita } \\
\text { Penyakit } \\
\text { Kulit }\end{array}$ & $\begin{array}{c}\text { Persentasi } \\
\text { (\%) }\end{array}$ \\
\hline 2012 & 77 & 1096 & 7,02 \\
\hline
\end{tabular}

Tabel 1 menujukkan jumlah penderita dermatitis kontak sebanyak 77 orang $(7,02 \%)$ dari 1.096 orang penderita baru penyakit kulit.

Tabel 2. Distribusi menurut umur

\begin{tabular}{|c|c|c|}
\hline UMUR & Frekuensi & $\mathbf{\%}$ \\
\hline$<1$ & 0 & 0 \\
$1-4$ & 2 & 2,6 \\
$5-14$ & 2 & 2,6 \\
$15-24$ & 15 & 19,5 \\
$25-44$ & 22 & 28,6 \\
$45-64$ & 29 & 37,7 \\
$\geq 65$ & 7 & 9 \\
\hline Total & 77 & 100 \\
\hline
\end{tabular}

Tabel 2 menunjukkan jumlah penderita dermatitis kontak terbanyak terdapat pada kelompok umur 45 - 64 tahun, yaitu sebanyak 29 orang $(37,7 \%)$ penderita.

Tabel 3.Distribusi menurut jenis kelamin

\begin{tabular}{|c|c|c|}
\hline $\begin{array}{c}\text { JENIS } \\
\text { KELAMIN }\end{array}$ & Frekuensi & $\mathbf{\%}$ \\
\hline Laki-Laki & 25 & 32,5 \\
Perempuan & 52 & 67,5 \\
\hline Total & 77 & 100 \\
\hline
\end{tabular}

Tabel 3 menunjukkan jenis kelamin terbanyak dermatitis kontak adalah perempuan, yaitu sebanyak 52 orang (67,5\%) penderita.

Tabel 4. Distribusi menurut pekerjaan

\begin{tabular}{|c|c|c|}
\hline PEKERJAAN & Frekuensi & \% \\
\hline IRT & 19 & 24,7 \\
Pelajar & 16 & 20,8 \\
PNS & 9 & 11,7 \\
Swasta & 7 & 9 \\
Buruh bangunan & 4 & 5,2 \\
Petani & 3 & 3,9 \\
Pendeta & 3 & 3,9 \\
Guru & 2 & 2,6 \\
Karyawan & 1 & 1,3 \\
Cleaning services & 1 & 1,3 \\
Penjahit & 1 & 1,3 \\
Tak bekerja & 11 & 14,3 \\
\hline Total & 77 & 100 \\
\hline
\end{tabular}

Tabel 4 menunjukkan pekerjaan paling banyak terjadi pada ibu rumah tangga, yaitu sebanyak 19 orang (24,7\%) penderita.

Tabel 5. Distribusi menurut lokasi

\begin{tabular}{|c|c|c|}
\hline LOKASI & Frekuensi & \% \\
\hline Kaki & 20 & 26 \\
Tangan & 16 & 20,8 \\
Tangan dan kaki & 13 & 16,9 \\
Kepala & 5 & 6,5 \\
Lengan bawah & 4 & 5,2 \\
Generalisata & 4 & 5,2 \\
Paha/tungkai bawah & 3 & 3,8 \\
Kepala + leher & 2 & 2,6 \\
Badan + selangkangan & 2 & 2,6
\end{tabular}




\begin{tabular}{|c|c|c|} 
Sekitar mulut & 2 & 2,6 \\
Badan + kaki & 1 & 1,3 \\
Ketiak & 1 & 1,3 \\
Telinga & 1 & 1.3 \\
Sekitar mata & 1 & 1,3 \\
Badan + tangan & 1 & 1.3 \\
Kepala + lengan bawah & 1 & 1,3 \\
\hline Total & 77 & 100 \\
\hline
\end{tabular}

Tabel 5 menunjukkan lokasi terbanyak terdapat pada kaki, yaitu sebanyak 20 orang (26\%) penderita.

Tabel 6. Distribusi menurut penyebab

\begin{tabular}{|c|c|c|}
\hline PENYEBAB & Frekuensi & \% \\
\hline Deterjen & 10 & 13 \\
Bahan karet & 10 & 13 \\
Bahan bangunan & 8 & 10,4 \\
Cuka & 3 & 3,9 \\
Minyak oles & 3 & 3,9 \\
Tanaman & 3 & 3,9 \\
Obat oles & 3 & 3,9 \\
Alkohol & 2 & 2,6 \\
Kosmetik & 2 & 2,6 \\
Bahan nikel & 2 & 2,6 \\
Plester & 2 & 2,6 \\
Sabun cuci piring & 2 & 2,6 \\
Cat rambut & 1 & 1,3 \\
Serbuk kayu & 1 & 1,3 \\
Daun teh & 1 & 1,3 \\
Air sumur & 1 & 1,3 \\
Pemutih pakaian & 1 & 1,3 \\
Parfum & 1 & 1,3 \\
Pasta gigi & 1 & 1,3 \\
Propolis & 1 & 1,3 \\
Minnyak oles + deterjen & 1 & 1,3 \\
Bahan karet + deterjen & 1 & 1,3 \\
Plester + obat oles & 1 & 1,3 \\
Tidak diketahui & 16 & 20,7 \\
\hline
\end{tabular}

\begin{tabular}{|c|c|c|}
\hline Total & 77 & 100 \\
\hline \multicolumn{3}{|c|}{$\begin{array}{l}6 \text { menunjukkan } \\
\text { adalah deterjen dan } \\
\text { ng-masing sebanyak } \\
\text { a. }\end{array}$} \\
\hline
\end{tabular}

10 orang (13\%) penderita. 
Tabel 7. Distribusi menurut terapi

\begin{tabular}{|l|c|c|}
\hline TERAPI & Frekuensi & \% \\
\hline Kortikosteroid topikal + Antihistamin topikal & 33 & 42,8 \\
Kortikosteroid topikal & 6 & 7,8 \\
Kortikosteroid toikal + Antihistamin oral + Antibiotik topikal + NaCl & 4 & 5,2 \\
Kortikosteroid topikal + Antihistamin oral + Antibiotik topikal & 4 & 5,2 \\
Kortikosteroid topikal + Antihistamin oral + Antifungi oral & 3 & 3,9 \\
Kortikosteroid topikal + Antihistamin oral + Antibiotik topikal + NSAID & 2 & 2,6 \\
Kortikosteroid topikal + Kortikosteroid oral + Antihistamin oral & 2 & 2,6 \\
Kortikosteroid topikal + Antibiotik oral + NaCl & 2 & 2,6 \\
Kortikosteroid topikal + Kortikosteroid oral + Antihistamin oral + NaCl & 2 & 2,6 \\
Antihistamin oral + Antibiotik topikal + NaCl & 2 & 2,6 \\
Kortikosteroid oral & 1 & 1,3 \\
Antihistamin oral & 1 & 1,3 \\
Kortikosteroid topikal + Antihistamin oral + PPI & 1 & 1,3 \\
Kortikosteroid topikal + Antibiotik oral + PPI & 1 & 1,3 \\
Kortikosteroid topikal + Antihistamin oral + Antibiotik oral + Antifungi oral & 1 & 1,3 \\
Kortikosteroid topikal + Antifungi oral & 1 & 1,3 \\
Kortikosteroid topikal + Kortikosteroid oral + Antihistamin oral + NSAID & 1 & 1,3 \\
Kortikosteroid topikal + Kortikosteroid oral + Antihistamin oral + Antifungi oral & 1 & 1,3 \\
Kortikosteroid topikal + Antihistamin oral + Antifungi topikal & 1 & 1,3 \\
Antihistamin topikal + Antipiretik oral + NaCl & 1 & 1,3 \\
Kortikosteroid topikal + Antihistamin oral + Antifungi oral + NaCl & 1 & 1,3 \\
Antibiotik oral + NSAID + NaCl & 1 & 1,3 \\
Antihistamin topikal + Antibiotik oral + NSAID + NaCl & 1 & 1,3 \\
Kortikosteroid topikal + Antihistamin oral + Antibiotik oral + PPI + NaCl & 1 & 1,3 \\
Kortikosteroid topikal + Antibiotik oral + NSAID + PPI + NaCl & 1 & 1,3 \\
Kortikosteroid topikal + Antihistamin oral + NaCl & 1 & 1,3 \\
Rujuk & 1 & 1,3 \\
\hline Total & 77 & 100 \\
\hline
\end{tabular}

Tabel 7 menunjukkan terapi paling banyak digunakan adalah Kortikosteroid dan Antihistamin yaitu sebanyak 33 orang (42,8\%).

\section{PEMBAHASAN}

Berdasarkan hasil penelitian didapatkan jumlah penderita baru yang didiagnosis dermatitis kontak sebanyak 77 orang (7.02\%) dari 1096 orang penderita baru penyakit kulit. Dibandingkan dengan penelitian Wulus ${ }^{8}$, ditemukan pada tahun terakhir yaitu 2005 penderita dermatitis kontak 5,84\% dari seluruh penyakit kulit rawat jalan. Hal ini menunjukkan angka kejadian dermatitis kontak mengalami peningkatan dari penelitian sebelumnya, dan mungkin disebabkan karena bertambahnya jumlah produk yang mengandung bahan kimia yang digunakan oleh masyarakat untuk aktivitas seharihari. $^{1}$

Berdasakan umur, dari hasil penelitian didapatkan bahwa kelompok umur terbanyak yang menderita dermatitis kontak adalah kelompok umur $45-64$ tahun, yaitu sebanyak 29 orang (37,7\%) penderita Hal ini berbeda dengan penelitian Wulus $^{8}$,yang mendapatkan kelompok umur tertinggi 25 - 44 tahun yaitu sebanyak 30,18\% . Hal ini mungkin karena orang yang lebih tua lebih rentan terpapar bahan-bahan iritan maupun alergen dan mungkin juga karena mereka lebih perduli dengan kesehatan mereka sehingga langsung berobat ke rumah sakit. Selain itu sesuai kepustakaan yang menyatakan bahwa dermatitis kontak lebih 
sering diderita orang dewasa walaupun sebenarnya dapat mengenai semua usia dan angka kejadian meningkat pada usia produktif. ${ }^{1}$ Hal ini terkait dengan pekerjaan dan kehidupan mereka seharihari yang mengharuskan terpapar dengan bahan-bahan iritan dan alergen.

Berdasarkan jenis kelamin, kejadian dermatitis kontak lebih banyak pada wanita yaitu sebanyak 52 orang (67,5\%) penderita daripada pria (2:1). Hasil ini sesuai dengan penelitian Wulus $^{8}$,yang mendapatkan 59\% dermatitis kontak terjadi pada wanita. Hal ini dikarenakan wanita lebih sering terpapar dengan berbagai bahan alergik maupun iritan dalam pekerjaan sehari-hari. Hal ini juga didukung kepustakaan yg menyatakan wanita dua kali lebih sering menderita dermatitis kontak dibandingkan pria. ${ }^{9}$

Berdasarkan pekerjaan dapatkan bahwa yang tertinggi menderita dermatitis kontak adalah ibu rumah tangga yaitu 19 orang $(24,7 \%)$ penderita. Hasil ini sesuai dengan penelitian Wulus $^{8}$, yang mendapatkan pekerjaan tertinggi ibu rumah tangga 21,62\%. Hal ini dikarenakan mereka dalam aktivitas sehari-hari melakukan pekerjaan-pekerjaan rumah tangga yg mengharuskan mereka terpapar dengan bahan iritan/alergik.

Berdasarkan lokasi, didapatkan yang tertinggi pada kaki, yaitu 20 orang (26\%) penderita. Hal ini ada hubungannya dengan penyebab yang ditemui yaitu bahan karet (sandal) sebagai penyebab kedua tertinggi karena berbagai produk alas kaki yang diproduksi sekarang ini terbukti bersifat alergen dan sandal juga merupakan jenis alas kaki tersering menyebabkan dermatitis ${ }^{5,10}$ Hasil ini berbeda dengan penelitian Wulus ${ }^{8}$,yang mendapatkan lokasi terbanyak pada tangan 25,22\%.

Berdasarkan penyebab, maka penderita dermatitis kontak paling banyak disebabkan oleh deterjen dan bahan karet, yaitu masing-masing sebanyak 10 orang (13\%) penderita. Hasil ini sama dengan penelitian Wulus ${ }^{8}$, dimana didapatkan penyebab terbanyak deterjen 9,9\%. Selain itu juga hasil sesuai kepustakaan yang menyebutkan penyebab tersering adalah sabun 22\% dan bahan karet 23,4\%. ${ }^{2}$ Hal ini disebabkan karena hampir semua orang terutama wanita menggunakan deterjen untuk berbagai aktivitas sehari-hari dan bahan karet (sandal) sesuai dengan predileksi terbanyak pada kaki. Dan didapatkan pada penderita-penderita dermatitis kontak 16 orang (20,7\%) diantaranya tidak diketahui penyebab yang pasti. Hal ini dapat disebabkan karena diagnosis yang ditegakkan hanya berdasarkan anamnesis dan pemeriksaan fisik saja tanpa adanya pemeriksaan penunjangyang berfungsi untuk menentukan penyebab dari dermatitis kontak alergi ini sendiri.

Berdasarkan terapi, didapatkan Kortikosteroid + Antihistamin merupakan terapi terbanyak yang diberikan kepada pasien yaitu sebanyak 33 orang (42,8\%). Hal ini sesuai kepustakaan yang menyebutkan bahwa terapi digunakan juga Kortikosteroid dan antihistamin untuk meringankan gejala yang timbul. ${ }^{1}$

\section{SIMPULAN}

Dari hasil penelitian retrospektif yang dilakukan selama periode Januari Desember 2012 pada pasien baru di Poliklinik Kulit dan Kelamin RSUP Prof. DR. R. D. Kandou, dapat disimpulkan dermatitis kontak terbanyak pada kelompok usia 45-64 tahun, jenis kelamin perempuan, pekerjaan ibu rumah tangga, lokasi tersering kaki, penyebab tersering deterjen dan karet, serta pemberian terapi tersering ialah kombinasi kortikosteroid dan antihistamin.

\section{SARAN}

Perlu dilakukan penelitian selanjutnya pada populasi yang lebih besar, untuk mendapatkan data prevalensi yang lebih lengkap.

\section{UCAPAN TERIMA KASIH}


Diberikan kepada dr. Renate T. Kandou, SpKK(K) dan dr. Nurdjannah J. Niode, SpKK selaku penguji I dan II serta semua pihak baik secara langsung maupun tidak langsung kepada semua pikah baik secara langsung maupun tidak langsung membantu penulis sehingga dapat menyelesaikan artikel ini.

\section{DAFTAR PUSTAKA}

1. Susanto SA, Djuanda S. Dermatitis. Dalam: Djuanda A, editor. Ilmu penyakit kulit dan kelamin. Edisi ke6. Jakarta: FKUI; 2010.h.129-38.

2. Mowad CM, Marks JG, Cohen DE, Friedmann PS, Wilkinson $M$. Papulosquamous and eczematous dermatoses. Dalam: Bolognia JL, Jorizzo JL, Rapini RP, editor. Dermatology. Edisi kedua. Philadelphia: Mosby Elvier; 2008.h.209-31.

3. Bogle MA, Militello G. Contact dermatitis. Dalam: Ali A, editor. Dermatology: a pictorial review. Edisi kedua. New York: McGrawHill; 2010.h.81-93.

4. Volcheck GW. Atopic and contact dermatitis. Dalam: Skolnik NS, editor. Clinical Allergy: diagnosis and management. Rochester: Humana press; 2009.h.333-53.

5. Fatinah A. Gambaran penyakit dermatitis kontak berdasarkan usia, jenis kelamin, gejala klinik serta predileksi di rumah sakit Immanuel Bandung periode januari 2011desember 2011. Bandung: Maranatha edu. 2012.201.h.1-2.

6. Nuraga $\mathbf{W}$, Lestari $F$, Kurniawidjaja LM. Dermatitis kontak pada pekerja yang terpajan dengan bahan kimia di perusahaan industri otomotif kawasan industri Cibitung Jawa Barat. Makara, kesehatan. 2008;12:63-9.

7. Royal collage of physician. Diagnosis, management and prevention of occupational contact dermatitis. 2011.[diakses 1 november
2013]. Diunduh dari: http://www.bad.org.uk/Portals/_Bad/ Guidelines/Clinical\%20Guidelines/R CP-BAD-BOHRF-FOMHWDU\%20Contact\%20dermatitis.pd f.

8. Wulus EN. Profil dermatitis kontak di Poliklinik Kulit dan Kelamin RSU Prof. Dr. R. D. Kandou Manado periode Januari 2001 - Desember 2005[Skipsi]. Manado: FK Unsrat; 2006.

9. Wilkinson SM, Beck MH. Contact dermatitis: irritant. Dalam: Burns T, Breathnach S, Cox N, Griffiths C, editor. Rook's: Textbook of dermatology. Chichester: Weleyblackwell. 2010.h.25.1.

10. Santiago F, Andiade P, Guncalo M, Mascarenhas $\mathbf{R}$, Figueiredo $\mathrm{A}$. Allergic contact dermatitis to shoes induced by dimethylfumarate. Dermatology online journal. 2010;16:1-4. 